\title{
De imigrantes pobres à classe médla: trajetória de uma família franco-argelina que contradiz as estatísticas
}

BEAUD, Stéphane. La France des Belhoumi. Portraits de famille (1977-2017). Paris: La Découverte, 2018, 346 p.

\section{Nadège Mézié*}

\section{Resumo}

No seu mais recente livro, La France des Belhoumi, objeto desta resenha, Stéphane Beaud faz o retrato dos membros de uma família de imigrantes argelinos instalados na França desde os anos 1970. Os oito filhos do casal tiveram uma trajetória social ascendente (passagem da classe popular à classe média) e é este percurso atípico para famílias de imigrantes argelinos na França que interessa ao sociólogo. Como em seus precedentes trabalhos, Beaud apoia-se numa perspectiva de sociologia qualitativa e apresenta um trabalho detalhado e instigante, de interesse para quem trabalhe com questões relativas à mobilidade social e ao sucesso escolar de crianças de camadas populares.

Palavras-chave: Mobilidade social, Imigrantes, França, Argélia, Sociologia da Educação.

* Universidade Paris-Descartes, Paris, França. 


\section{From poor immigrants to the middle class: the path of a Franco- Algerian family that contradicts statistics}

\section{Abstract}

In his latest book, La France des Belhoumi, the subject of this review, Stéphane Beaud portrays the members of a family of Algerian immigrants settled in France since the 1970s. The eight children of the couple had an upward social trajectory (passage of the popular class to the middle class) and it is this atypical course for families of Algerian immigrants in France that interests the sociologist. As in his previous works, Beaud is based on a qualitative sociological perspective and presents a detailed and stimulating work of interest for those who work with issues related to social mobility and the success of schoolchildren.

Keywords: Social mobility, Immigrants, France, Algeria, Sociology of Education.

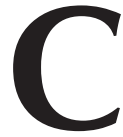

om o final da segunda guerra mundial, a França necessitava de trabalhadores para reconstruir o país, que entrava numa nova fase de modernização graças à economia florescente da época. Homens vindos da África do Norte, e em particular da Argélia (colônia francesa até 1962, quando conquistou sua independência), formaram o maior contingente de mão de obra estrangeira presente em solo francês até os anos 1970. Com efeito, durante o período conhecido como Trente Glorieuses (de 1945 até a primeira crise petrolífera em 1973), centenas de milhares de argelinos migraram para a França, sem que, no entanto, essa imigração tenha sido oficialmente estimulada pelo governo francês ${ }^{1}$. Sabendo das ofertas de emprego, esses "trabalhadores imigrantes" (travailleurs immigrés), em sua grande maioria homens de confissão muçulmana, vinham seguindo os passos de primos, tios, conhecidos. Noventa por cento deles se tornaram

${ }^{1}$ Sobre a imigração argelina na França e sua história ver, entre outros, Blanchard (2018), Stora (1992) e Silverstein (2004). 
operários na indústria e na construção civil². Até 1962, enquanto a Argélia era colônia francesa ${ }^{3}$, e mesmo na primeira década após sua independência, havia "uma relativa liberdade de circulação" entre os dois países (Blanchard, 2018, p. 75), o que facilitava a entrada desses homens na França.

Passados alguns anos, muitos tentaram trazer mulher e filhos que tinham ficado no país de origem. Se havia políticas de reunião familiar nas quais podiam se apoiar, essas políticas eram bastante restritivas e muitos permanecem sozinhos na França até a aposentadoria ou o falecimento. Boa parte desses trabalhadores, com ou sem suas famílias, vai se instalar em moradias extremamente precárias, verdadeiras favelas (bidonvilles), como a emblemática La Folie de Nanterre ${ }^{4}$. Aos poucos, a partir do final dos anos 1950, construíram-se conjuntos habitacionais, sobretudo nas periferias (banlieues) das grandes cidades. Hoje em dia ainda, argelinos e portugueses são os estrangeiros mais representados no território francês (cerca de 500000 indivíduos de cada uma dessas nacionalidades) e, em 2013, os filhos de argelinos, mais de um milhão, compunham o maior grupo de pessoas "oriundas da imigração" (d'origine immigrée) na França, seguidos dos filhos de italianos e de portugueses (Blanchard, 2018, p. 6).

A discriminação e estigmatização que estes argelinos e seus descendentes enfrentaram e continuam a enfrentar sempre foi muito intensa. Além de imigrantes pobres (ou filhos e netos deles), trata-se de uma população majoritariamente muçulmana ${ }^{5}$, originária de um país cuja relação com

${ }^{2} \mathrm{~A}$ fábrica de carros Renault-Billancourt, situada no sudoeste da cidade de Paris, chegou a empregar 3500 operários argelinos (o que representava 11,5\% da totalidade dos operários). Esta imensa unidade fabril da Renault tornou-se, assim, nos anos 1950, o maior empregador de argelinos tanto na França quanto na Argélia (Pitti, 2007).

${ }^{3}$ Sobre a condição e o enquadramento legal atribuído pela França aos argelinos muçulmanos, e suas mudanças ao longo do tempo (mesmo durante a época colonial), ver Weil (2005).

${ }^{4} \mathrm{~A}$ respeito, ver a reportagem "1963 : Le bidonville de Nanterre", disponível em: https:// www.youtube.com/watch? $=$ hQnvR-EpHV4, e o livro de Sayad (2008).

${ }^{5}$ Se há uma grande heterogeneidade na relação da "segunda e terceira gerações" (filhos e netos dos primeiros membros da família a imigrar) com o Islã - que vai da reafirmação de sua fé de maneira ainda mais marcada que seus pais ou avós, até um distanciamento ou uma prática mais cultural que propriamente religiosa do Islã -, essas pessoas continuam a ser frequentemente associadas pela mídia e por muitos franceses à religião muçulmana. 
a França foi durante décadas extremamente conflituosa, mais que em outras colônias (guerra de independência que durou oito anos, diversos atos de terrorismo organizados tanto na França quanto na Argélia nos anos 1990). A recente onda de atentados terroristas reivindicados pela organização Estado Islâmico, assim como a polêmica em torno da lei que proíbe o uso do véu islâmico em escolas públicas (lei de 2004) e o debate promovido pelo presidente Nicolas Sarkozy (2007-2012) sobre o que seria a verdadeira "identidade nacional" são eventos que influem sobre a percepção que o conjunto da sociedade francesa tem desta população, e dificultam sua integração. A partir dos anos 1990, com o significativo aumento do desemprego, o "problema das banlieues" ganha espaço no discurso de políticos e jornalistas que passam a focalizar os "jovens delinquentes oriundos da imigração", que "se radicalizam" na sua prática do Islã. Fala-se então do "fracasso" do modelo de integração francês. Os pesquisadores de Ciências Sociais que assumem uma perspectiva crítica - e Stéphane Beaud está entre eles - analisam os processos de categorização de certos fatos como "problema social" e propõem outras leituras da realidade dos bairros populares franceses e de seus habitantes.

Atualmente professor de sociologia na universidade de Poitiers, Stéphane Beaud fez sua tese sob a direção do sociólogo Jean-Claude Chamboredon (colega e colaborador de Pierre Bourdieu) e dedicou seus primeiros estudos, realizados em conjunto com o sociólogo Michel Pialoux, à condição dos operários na França contemporânea, à transformação do trabalho nas fábricas (Pialoux; Beaud, 1999) e às relações entre trabalhadores franceses e imigrantes (Pialoux; Beaud, 1998). Nos trabalhos seguintes - ver, por exemplo, Beaud (2002) e, com Younes Amrani (Amrani; Beaud, 2005) -, Beaud volta sua atenção para a escolarização dos jovens de famílias populares, filhos de imigrantes que residem nas banlieues, destacando as importantes dificuldades que estes jovens encontram em seu percurso 
escolar, universitário e evocando sua difícil inserção profissional ${ }^{6}$. No seu mais recente livro, La France des Belhoumi (2018) ${ }^{7}$, objeto desta resenha, Beaud faz, em certa medida, o caminho inverso, interessando-se por uma família de imigrantes cujos filhos tiveram uma trajetória social ascendente (passagem da classe popular à classe média). Dessa maneira, inspirandose nos trabalhos do sociólogo Abdelmalek Sayad e do historiador Gérard Noiriel, Beaud, propõe-se a contribuir para "uma contra-história dos descendentes de imigrantes argelinos na França" (p. 11, tradução nossa) - "contra-história", na medida em que as famílias de origem argelina que tiveram trajetórias ascendentes são minoritárias na França.

O livro La France des Belhoumi, escrito numa linguagem voluntariamente acessível a um público não especialista, estrutura-se em torno de retratos dos membros desta família. Encontramos, assim, o retrato do casal que chegou à França nos anos 1970 e de seus três filhos e cinco filhas, nascidos entre 1970 e 1986, os três primeiros na Argélia e os demais na França. Como em todos os seus precedentes trabalhos, Beaud adota uma perspectiva de sociologia qualitativa. Para esta pesquisa, realizou entrevistas repetidas durante cinco anos com cada membro da família e, através de e-mails e SMS (trechos são mobilizados no texto), manteve uma relação próxima com vários deles, sobretudo as irmãs mais velhas. Beaud afirma ter apresentado e discutido suas análises com os irmãos Belhoumi em diversas ocasiões no decorrer da pesquisa, o que lhe permitiu ao mesmo tempo aprofundar certos aspectos da análise e fornecer instrumentos de reflexão aos seus interlocutores. Ele inspira-se e afilia-se, assim, às reflexões de Pierre Bourdieu em A miséria do mundo (2008) ou Esboço de autoanálise (2005), para quem um olhar sociológico sobre sua própria trajetória é capaz de promover uma reflexividade emancipatória.

${ }^{6}$ Em paralelo, Beaud trata também dos discursos e polêmicas que suscita, desde 2010, a seleção nacional de futebol francesa, formada essencialmente por jovens descendentes de imigrantes (Beaud, 2011; 2014).

${ }^{7}$ Vale lembrar que, para garantir o anonimato de seus interlocutores, Beaud alterou todos os nomes e sobrenomes, assim como nomes de bairros e cidades citadas no livro. 
O livro é composto de três partes e um capítulo inicial que as precede, dedicado à história dos pais na Argélia e na França. Neste capítulo-preâmbulo, lê-se que os pais se casam em 1968 na Argélia, ela com 16, ele com 26 anos. Oriundos de famílias pobres, ambos tinham pouco estudo. A mãe, no entanto, morou por dez anos com uma conhecida da família que tinha melhores condições materiais e frequentou durante esse período uma escola francesa. Os conhecimentos adquiridos na língua francesa the permitirão, mais tarde, lidar com mais facilidade do que outros imigrantes com as exigências administrativas da vida na França e também acompanhar melhor a escolarização dos filhos, o que será um diferencial importante. Em busca de trabalho, o pai migra para França em 1971; é recebido na casa de parentes e passa por diferentes cidades trabalhando na construção civil. O casal continua a se encontrar uma vez por ano, nas férias do marido. Seis anos e muitas negociações familiares depois, vêm a esposa e os filhos. A família se instala em um conjunto habitacional destinado a famílias de baixa renda $\left(\mathrm{HLM}^{8}\right)$, numa banlieue de uma cidade média do centro da França. O pai terá, no entanto, uma vida profissional curta. Em razão de infeções pulmonares à repetição, ele é declarado inválido em 1978 e passa a receber uma pequena pensão mensal. A esposa consegue um emprego como agente de limpeza num colégio e os "bicos" (jobs) das duas filhas mais velhas serão essenciais para completar a renda familiar.

O livro continua, em sua primeira parte, intitulada "As cinco irmãs: escola e emancipação", com a descrição da trajetória das filhas Belhoumi. Beaud analisa e compara o percurso das duas filhas mais velhas e das três mais novas (aproximadamente 10 anos separam os dois grupos de irmãs). As mais velhas prosseguiram sua escolaridade até o mestrado, ainda que, a partir dos 14 anos, ambas tenham passado a trabalhar sempre que não estavam na escola ${ }^{9}$ e durante as férias, como diaristas e educadoras sociais: “Elas foram, de maneira precoce, um verdadeiro pilar de apoio financeiro à família, condição profundamente respeitada, especialmente pelos irmãos

${ }^{8}$ Sigla para Habitation à Loyer Modéré (habitação de aluguel moderado).

${ }^{9} \mathrm{~A}$ escola na França é de tempo integral (8h30 às 16h30). 
e irmãs mais novos", afirma Beaud (p. 77, tradução nossa). Logo após a conclusão do mestrado, as duas conseguem um emprego: uma como enfermeira (ela logo evoluiu para a função de gerente administrativa em hospitais) e a outra como conselheira num programa de inserção profissional destinado a jovens. Elas se tornam, desde a adolescência, as "locomotivas" do grupo de irmãos, apoiando cada um deles em seus estudos, ajudando-os a não entrar (ou a sair rapidamente) da delinquência e a achar rapidamente um trabalho, estimulando o hábito da leitura. As três irmãs mais novas obtiveram "apenas" uma graduação (em enfermagem, administração e serviço social) e também se inseriram rapidamente e de forma duradoura no mercado de trabalho. Quanto ao matrimônio e à maternidade, as mais velhas adiaram o máximo possível a entrada na condição de mãe e esposa, casaram-se com 33 e 39 anos. Já as mais jovens casaram-se aos vinte e poucos anos e tiveram logo um filho.

Para melhor entender essas diferenças, além das particularidades da trajetória dessa família e de cada um dos seus membros, o sociólogo apresenta um histórico da evolução da vida do bairro, contextualizando-a no cenário político e econômico nacional. Na década de 1980 e primeira metade da década de 1990, durante o governo Mitterrand ${ }^{10}$ (período que corresponde à infância e juventude das irmãs mais velhas), havia uma maior presença de associações culturais e esportivas no bairro (uma das irmãs mais velhas as frequentava sistematicamente); entre os moradores, a heterogeneidade social também era maior, com a presença de famílias não oriundas da imigração e mesmo algumas famílias de classe média; nas escolas, era comum a existência de diversos professores, e sobretudo professoras, militantes de esquerda, que se davam por missão a integração bem sucedida de crianças de famílias de imigrantes, sobretudo das meninas (a fim de evitar-lhes um casamento precoce e "arranjado", comum na Argélia). As duas irmãs mais velhas têm lembranças de professores que as influenciaram profundamente. Havia, portanto, todo um "clima", um conjunto de fatores políticos e sociais, que Beaud acredita ter influenciado

${ }^{10}$ François Mitterrand foi presidente da França pelo Partido Socialista de 1981 a 1995. 
a história das irmãs, contribuindo para que as mais velhas alcançassem diplomas e posições profissionais mais valorizadas e se casassem mais tarde. Por fim, diversas pesquisas indicam que o investimento e a expectativa dos pais de famílias numerosas tendem a ser mais sistemáticos ou intensos em relação à escolaridade dos filhos e filhas mais velhos (Moguérou, 2013; Wolff, 2013), o que Beaud acredita ter também acontecido na família Belhoumi. A posição social e profissional das três irmãs mais novas, contudo, apesar de menos prestigiosa do que a das irmãs mais velhas, fica ainda claramente acima da média daquela de outras meninas do bairro, que muitas vezes não obtém o diploma de conclusão do Ensino Médio (baccalauréat ${ }^{11}$ ) e se tornam manicures, diaristas, caixas de supermercado, donas de casa.

Na segunda parte do livro, intitulada "Os três irmãos sob a proteção atenta das irmãs mais velhas", Beaud trata da trajetória dos filhos Belhoumi. Nascidos entre as duas irmãs mais velhas e as três mais novas, os meninos tiveram um percurso escolar com mais percalços ${ }^{12}$. Apesar de terem terminado o Ensino Médio, dois não obtiveram o diploma (baccalauréat), o terceiro obteve um baccalauréat mas numa modalidade profissionalizante (muito menos prestigiosa que o "bac geral", já que não permite o ingresso na universidade). Um deles entrou numa curta carreira de delinquência e chegou a ser preso. Ainda assim, desde que começaram a trabalhar, os três nunca ficaram desempregados, o que os distingue assim da maior parte de seus amigos do bairro. E essa diferença, os rapazes atribuem ao apoio que receberam das tão admiradas irmãs mais velhas. Enquanto elas moravam com os pais, as duas ajudavam os irmãos (e irmãs) em seus deveres de casa, compravam materiais escolares com o dinheiro que recebiam de seus "bicos", Ihes ofereciam livros e lhes davam, em troca de uma ficha de leitura feita durante as férias, um valor equivalente a um lanche. Quando passaram a morar sozinhas, elas recebiam os irmãos durante feriados (ou

${ }^{11} \mathrm{O}$ baccalauréat, ou bac, como é conhecido, é um exame realizado no final do Ensino Médio, similar ao ENEM no Brasil. Porém, diferente deste, aqueles alunos que não obtêm a média no bac, não recebem o diploma de conclusão do Ensino Médio.

${ }^{12}$ Outras pesquisas indicam que meninas de classes populares tendem a ter um desempenho escolar superior ao de meninos (Carvalho et al. 2014; Depoilly, 2012; Terrail, 1992). 
quando eles não estavam mais na escola, por estadias tão longas quanto dois anos), os levavam a exposições, tinham inúmeras conversas, discussões, ajudavam a procurar emprego, a melhorar a redação ou apresentação dos currículos. Os irmãos mencionam repetidas vezes esse apoio: "elas 'tavam sempre lá, sempre me puxando" (p. 184). "Puxando" para ajudá-los também a enfrentar as frequentes situações de racismo e discriminação a que eram expostos: serem parados pela polícia sem motivo aparente, ouvirem de potenciais empregadores e de cidadãos franceses em geral comentários carregados de preconceitos, verem recusada uma vaga de trabalho também sem motivo aparente. As meninas, tanto as mais velhas como as mais novas, relatam ter enfrentado menos esse tipo de situação. Nesse ponto, os dados apresentados por Beaud corroboram os de outras pesquisas que indicam que a experiência de discriminação dirigida a jovens homens "de periferia", sobretudo em espaços públicos, é mais forte que aquela de jovens mulheres ${ }^{13}$. Vale notar que Beaud não é o primeiro a ter destacado o papel de apoiadores, e mesmo de modelos, que irmãs ou irmãos mais velhos podem ter em famílias numerosas. Pensamos, por exemplo, nos trabalhos de Buisson (2003) ou de Vanhée e colaboradores (2013).

Para compreender as trajetórias dos irmãos Belhoumi que, em muitos aspectos, diferem daquelas de outras pessoas do bairro popular no qual eles cresceram - tanto no caso das meninas quanto dos meninos -, Beaud considera diversas instâncias de socialização que foram importantes nas experiências dos irmãos: a família (pais e, como vimos, os irmãos), a escola, mas também o papel de associações culturais e esportivas e da sociabilidade da rua. Na linha dos trabalhos de Bernard Lahire e do seu livro Tableaux de famille (1995) ${ }^{14}$, Beaud não se satisfaz com o fator "classe social dos pais" para explicar a trajetória escolar dos oito filhos. Ele tampouco acredita na ideia de "um fator central", um premium mobile

${ }^{13}$ Ver Safi (2013) ou Simon e Safi (2014) para o contexto francês. No Brasil, Monteiro e Cecchetto (2009) fazem uma constatação similar.

${ }^{14}$ Traduzido para o português sob o título de Sucesso escolar nos meios populares: as razões do improvável (1997). 
(a militância ou o caráter autodidata de pelo menos um dos membros da família, por exemplo). À maneira de Lahire, ele inscreve sua análise numa "antropologia da interdependência", ou seja, numa análise baseada na combinação de múltiplos fatores interconectados e numa contextualização histórica detalhada.

Na terceira parte do livro, intitulada "A relação do grupo de irmãos com o político e com a religião", Beaud descreve e analisa a construção e as transformações dessas relações ao longo dos anos, contextualizando-as com dados de outras pesquisas. $\mathrm{O}$ engajamento de uma das irmãs mais velhas em associações ligadas ao Partido Comunista Francês (PCF) permite que Beaud aborde as relações complexas dos partidos de esquerda franceses com os imigrantes (discursos em fase com muitos de seus interesses, práticas nem sempre) e mostre as mudanças em relação ao político, observadas entre a geração que imigrou para a França e as gerações nascidas no país. $\mathrm{O}$ penúltimo capítulo é dedicado à reação e aos pensamentos dos irmãos sobre os atentados que aconteceram em Paris em 2015 (ao jornal satírico Charlie Hebdo em janeiro e na casa de shows Bataclan em novembro). Enquanto as irmãs mais velhas e uma das mais novas se identificaram imediatamente ao "Je suis Charlie ${ }^{15 "}$ e se irritavam com colegas de trabalho que as questionavam sobre suas posições (elas se sentiam ofendidas por não considerarem óbvia sua posição contrária aos atentados), os outros irmãos oscilaram entre toda uma gama de posições que foram desde "Mas os jornalistas do Charlie provocaram...16", até uma adesão a teorias conspiracionistas (o atentado teria sido orquestrado por governos ocidentais, sua dimensão aumentada por jornalistas) ou ainda uma posição intermediária, condenando os terroristas sem no entanto se "sentir Charlie". As irmãs mais velhas tiveram, mais uma vez, uma forte influência sobre irmãos, temperando suas críticas e exercendo um verdadeiro controle sobre o que eles postavam nas redes sociais. A

${ }^{15}$ Hashtag de repúdio ao atentado.

${ }^{16} \mathrm{O}$ jornal publica regularmente caricaturas de todo tipo de figuras públicas e históricas e havia publicado algumas do profeta Maomé, que muitos muçulmanos consideram como ofensivas 
prática religiosa é o tema do último capítulo e afirma-se de novo, ali, uma diferença geracional: as irmãs mais novas e um dos irmãos experimentam um revival religioso, enquanto as mais velhas se distanciam cada vez mais de qualquer prática religiosa, e outros dois irmãos a praticam sem fervor.

Através da diversidade de percursos e de posicionamentos no interior da família Belhoumi, é possível ter uma ideia das preocupações que habitam os jovens franceses "oriundos da imigração" argelina e da diversidade presente neste meio social. Ter descrito com grande fineza de detalhes e ter tentado explicar as diferenças entre as trajetórias das irmãs e dos irmãos, e as diferenças entre as irmãs mais velhas e as mais novas, são os grandes méritos deste livro. A contextualização histórica e social, sólida e ampla, permitiu que Beaud evitasse a armadilha de uma explicação culturalista redutora (eles agem assim por serem argelinos, árabes, muçulmanos etc.). A escolha dos retratos como forma de apresentar os dados permite trazer à tona particularidades do percurso de cada membro da família, a multiplicidade de motivos e fatores explicativos e a heterogeneidade que existe dentro do grupo de irmãos. Beaud evita, assim, qualquer generalização excessiva. Quem busca um desenvolvimento teórico ou um esforço sistemático de conceitualização de temas abordados no livro (sucesso escolar, mobilidade social, integração), no entanto, não os encontrará no trabalho de Beaud. O que alguns podem perceber como um ponto frágil da obra, me parece uma opção deliberada do autor, que põe a ênfase nos dados empíricos, sempre contextualizados histórica e socialmente, e nas falas (e escritos, no caso de e-mails e SMS) de seus interlocutores.

Para além do contexto francês, o livro deve interessar diretamente a pesquisadores que trabalham sobre mobilidade social, suas razões e implicações, e sobre a questão da integração de filhos de imigrantes. Ele é também uma leitura de grande interesse para os que querem entender melhor o como do sucesso escolar de crianças de famílias populares, dialogando assim com o trabalho de Bernard Lahire, mas também, no Brasil, com os trabalhos de Nadir Zago (2001), Norberto Dallabrida e colaboradores (2014) e Maria José Braga Viana (2007). Para o leitor que 
se interesse por esta questão, recomendo igualmente dois livros franceses relativamente recentes que dialogam com o trabalho de Beaud e trazem elementos bastante interessantes para a compreensão do "sucesso escolar", considerando não só a Educação Básica, mas a entrada no Ensino Superior de jovens de bairros populares: Jeunesses Françaises. Bac +5 made in banlieue (2015), do sociólogo Fabien Truong, publicado na mesma coleção do livro de Beaud (coleção L'envers des faits, da editora La Découverte) e Passer les frontières sociales. Comment les "filières d'élite" entrouvrent leurs portes (2014), do sociólogo Paul Pasquali, que realizou sua tese sob orientação de Beaud.

Nadège Mézié é Doutora em Antropologia pela Universidade Paris-Descartes. Realizou pósdoutorado no Programa de Pós-Graduação em Antropologia Social da UFRGS e foi professora substituta (ATER) na Faculdade de Ciências Sociais da Universidade Paris-Descartes (20162018). É pesquisadora associada do Núcleo de Estudos da Religião (NER/UFRGS), Grupo de Pesquisa Sobre Naturezas e Centre d'Anthropologie Culturelle (CANTHEL/Paris Descartes).

$\equiv$ nadege.mezie@wanadoo.fr

\section{Referências}

1. AMRANI, Younes; BEAUD, Stéphane. "Pays de malheur!" Un jeune de cité écrit à un sociologue. Paris: La Découverte, 2005.

2. BEAUD, Stéphane. $\mathbf{8 0} \%$ au bac! Et après?... Les enfants de la démocratisation scolaire. Paris: La Découverte, 2002.

3. BEAUD, Stéphane. Traîtres à la nation ? Un autre regard sur la grève des Bleus en Afrique du Sud. Paris: La Découverte, 2011.

4. BEAUD, Stéphane. Affreux, riches et méchants ? Un autre regard sur les Bleus. Paris: La Découverte, 2014.

5. BEAUD, Stéphane. La France des Belhoumi. Portraits de famille (1977-2017). Paris: La Découverte, 2018.

6. BLANCHARD, Emmanuel. Histoire de l'immigration algérienne en France. Paris: La Découverte, 2018.

7. BOURDIEU, Pierre (Org.). A miséria do mundo. Rio de Janeiro: Editora Vozes, 2008. 
8. BOURDIEU, Pierre. Esboço de auto-análise. São Paulo: Companhia das Letras, 2005.

9. BUISSON, Monique. La fratrie, creuset des paradoxes. Paris: Harmattan, 2003.

10. CARVALHO, Marília P. de; SENKEVICS, Adriano S.; LOGES, Tatiana A. O sucesso escolar de meninas de camadas populares: qual o papel da socialização familiar. Educação \& Pesquisa, São Paulo, v. 40, n. 3, p. 717-34, 2014.

11. DALLABRIDA, Norberto, MELLO, Juliana T. S.; MARTINI, Estela M. S.; VIEIRA, Letícia. Herdeiros/as e trânsfugas: carreiras profissionais de ex-alunos/ as de colégios de ensino secundário de Florianópolis da década de 1950. In: DALLABRIDA, Norberto; SOUZA, Rosa. F. de. (Orgs.). Entre o ginásio de elite e o colégio popular: estudos sobre o ensino secundário no Brasil (1931-1961). Uberlândia: EDUFU, 2014, p. 61-87.

12. DEPOILLY, Séverine. Des filles conformistes? Des garçons déviants? Manières d'être et de faire des élèves de milieux populaires. Revue Française de Pédagogie, v. 179, p. 17-28, 2012.

13. LAHIRE, Bernard. Tableaux de familles. Heurs et malheurs scolaires en milieux populaires. Paris, Seuil/Gallimard, 1995 [Tradução: Sucesso escolar nos meios populares: as razões do improvável. São Paulo: Editora Ática, 1997)].

14. MOGUÉROU, Laure. L'aide au travail scolaire dans les familles immigrées de milieux populares. Migrations Société, v. 25, n. 147-148, p. 159-74, 2013.

15. MONTEIRO, Simone; CECCHETTO, Fatima. Cor, gênero e classe: dinâmicas da discriminação entre jovens de grupos populares cariocas. Cadernos Pagu, n. 32, p. 301-29, 2009.

16. PASQUALI, Paul. Passer les frontières sociales. Comment les « filières d'élite » entrouvrent leurs portes. Paris: Fayard, 2014.

17. PIALOUX, Michel; BEAUD, Stéphane. Retour sur la condition ouvrière. Enquête aux usines Peugeot-Sochaux. Paris: Fayard, 1999.

18. PIALOUX, Michel; BEAUD, Stéphane. Notes de recherche sur les relations entre Français et immigrés dans l'usine et le quartier. Genèses, v. 30, 1998.

19. PITTI, Laure. Carrières d'OS dans I'automobile au XXe siècle. Le cas d'école des Algériens à Billancourt. In: COSTA-LASCOUX, Jacqueline; TEMIME, Émile. (Orgs.) Renault sur Seine. Hommes et lieux de mémoire de l'industrie automobile. Paris: La Découverte, 2007, p. 97-111.

20. TRUONG, Fabien. Jeunesses françaises. Bac +5 made in banlieue. Paris: La Découverte, 2015.

21. SAFI, Mirna. Les inégalités ethno-raciales. Paris: La Découverte, 2013.

22. SAYAD, Abdelmalek. Un Nanterre algérien, terre de bidonvilles. Paris: Autrement, 2008.

23. SILVERSTEIN, Paul A. Algeria in France. Transpolitics, race, and nation. Bloomington/Indianapolis: Indiana University Press, 2004. 
24. SIMON, Patrick; SAFI, Mirna. Les discriminations ethniques et raciales dans I'enquête Trajectoires et Origines: représentations, expériences subjectives et situations vécues. Économie et statistique, Paris, n. 464-465-466, p. 245-75, 2013.

25. STORA, Benjamin. Ils venaient d'Algérie. L'immigration algérienne en France 1912-1992. Paris: Fayard, 1992.

26. TERRAIL, Jean-Pierre. Réussite scolaire: la mobilisation des filles. Sociétés Contemporaines, Paris, n. 11-12, p. 53-89, 1992.

27. VANHÉE, Olivier et al. La fratrie comme ressource. Le rôle des aînés dans les parcours scolaires des enfants de familles nombreuses. Revue des Politiques Sociales et Familiales, Paris, n. 111, p. 5-15, 2013.

28. VIANA, Maria J. B. Longevidade escolar em famílias de camadas populares: algumas condições de possibilidade. Goiânia: UCG - Editora da Universidade Católica de Goiás, 2007.

29. WEIL, Patrick. Le statut des musulmans en Algérie coloniale. Une nationalité française dénaturée. Histoire de la Justice, v. 1, n. 16, p. 93-109, 2005.

30. WOLFF, François C. Inégalités d'éducation et de position sociale au sein des fratries. Revue des Politiques Sociales et Familiales, Paris, n. 11, p. 31-41, 2013.

31. ZAGO, Nadir. Quando os dados contrariam as previsões estatísticas: os casos de êxito escolar nas camadas socialmente desfavorecidas. Cadernos de Psicologia e Educação - Paidéia, USP/Ribeirão Preto, v. 10, n. 18, p. 70-80, 2001.

Recebido: 04 out. 2018

Aceito: 20 nov. 2018 